\title{
NON-CONTACT THERMOMETER BERBASIS INFRA MERAH
}

\author{
Meilia Safitri \\ Program Vokasi, Program Studi Teknik Elektromedik \\ Universitas Muhammadiyah Yogyakarta \\ Email: meilia.safitri@ vokasi.umy.ac.id \\ Gusti Arya Dinata \\ Program Vokasi, Program Studi Teknik Elektromedik \\ Universitas Muhammadiyah Yogyakarta \\ Email: gusti.arya.2014@vokasi.umy.ac.id
}

\begin{abstract}
ABSTRAK
Pengukuran terhadap suhu tubuh manusia dapat dilakukan dengan menggunakan termometer badan. Jenis termometer badan yang sudah ada saat ini beberapa diantaranya adalah termometer badan analog dan termometer badan digital. Pada umumnya alat-alat tersebut membutuhkan waktu paling cepat selama satu hingga dua menit sampai didapatkan nilai suhu tubuh manusia, sehingga dibutuhkan cara baru untuk mendapatkan nilai suhu tubuh dengan waktu lebih singkat tanpa mengorbankan keakuratan. Dalam penelitian ini telah dirancang sebuah alat yang dapat digunakan untuk mengetahui nilai suhu tubuh manusia dengan waktu yang singkat dan menghasilkan nilai pembacaan yang akurat. Menggunakan sensor infra merah dengan seri MLX90614 yang dipadukan dengan Arduino Nano serta tampilan LCD OLED 128x64 merupakan cara yang digunakan untuk membuat termometer tubuh tanpa kontak fisik. Metode penelitian yang digunakan yaitu membandingkan antara alat non-contact thermometer dengan alat pembanding. Alat pembanding ini sebagai acuan untuk mendapatkan nilai presisi dan akurasi yang tinggi. Kedua alat melakukan pengukuran suhu dalam kondisi yang sama.
\end{abstract}

Kata kunci: arduino nano; melexis MLX90614; infra merah; radiasi gelombang elektromagneti; suhu.

\begin{abstract}
The measurement of human body temperature is done using mercury based mes thermometer. There are many kinds of body thermometer like non-digital mercury thermometer and digital mercury thermometer. Mostly of the body temperature measuring methods need one until two minutes to acquire the value of body temperature. In this study a tool that could measure the temperature of human body with faster way without sacrificing the accuracy is build. The research is trying to build a tool that can be used to measure human body temperature in the fast and accurate way. Using infrared thermometer sensor made by Melexis MLX90614 series based on Arduino Nano and LCD OLED $128 x 64$ as the informator is the way to make the idea realized. The research method used is comparing between noncontact thermometer with comparison device. This comparison device is a reference to get a high precision and accuracy value. Both devices take temperature measurement under the same conditions
\end{abstract}

Keywords: arduino nano; melexis MLX90614; infrared; radiation of electromagnetic wave; temperature.

\section{PENDAHULUAN}

Panas dan suhu adalah dua hal yang berbeda. Panas adalah energi total dari gerak molekular di dalam zat, energi panas bergantung pada kecepatan partikel, jumlah partikel (ukuran atau massa), dan jenis partikel di dalam sebuah benda. Suhu adalah ukuran energi rata-rata dari gerak molekular di dalam zat. Secara sederhana suhu didefinisikan sebagai derajat panas atau dinginnya suatu benda [1].

Suhu tubuh merupakan salah satu tanda vital yang mempunyai arti sebagai indikasi adanya kegiatan organ-organ di dalam tubuh [2]. Pemeriksaan tanda vital adalah suatu cara untuk mendeteksi adanya perubahan sistem tubuh. Pengkajian/pemeriksaan tanda vital digunakan untuk memantau perkembangan pasien dan mengetahui adanya kelainan pada tubuh dimanfaatkan sebagai salah satu penyokong dalam membantu menentukan diagnosa. Tindakan ini bukan hanya sekedar rutinitas tetapi merupakan tindakan pengawasan terhadap perubahan/gangguan sistem tubuh. Untuk mengetahui suhu tubuh diperlukan alat pengukur suhu yang salah satunya adalah termometer[3]. 
Pada umumnya termometer yang sering digunakan untuk mengukur suhu tubuh manusia terbagi menjadi 2 yaitu analog dan digital. Terdapat pula termometer yang menggunakan air raksa. Apabila tabung pecah, air raksa merupakan zat yang beracun bagi manusia. Pada umumnya termometer analog maupun digital sama-sama membutuhkan waktu pengukuran suhu dalam hitungan menit dan menimbulkan kekhawatiran terjadinya infeksi nosokomial karena adanya kontak langsung dengan tubuh[4]. Sekitar 5-15\% penderita yang dirawat di rumah sakit mengalami infeksi nosokomial. Bakteri stafilokokus dan Vancomycin-Resistant Enterococci (VRE) dapat berkembang penularannya lewat media alat kesehatan yang langsung digunakan perawat kepada pasien, seperti termometer[5]. Para perawat melakukan pemeriksaan suhu tubuh pasien setiap pagi, siang, dan sore. Setiap pasien tidak mendapatkan termometer secara individual, sehingga dikhawatirkan bahwa bakteri dari satu pasien akan menyebar ke pasien lainnya melalui termometer[6].

Salah satu usaha yang dapat dilakukan untuk mencegah penyebaran bakteri stafilokokus dan Vancomycin-Resistant Enterococci (VRE) adalah dengan menggunakan termometer yang tidak bersentuhan langsung dengan kulit manusia (non-contact thermometer). Penggunaan inframerah menjadi salah satu opsi dalam mengembangkan termometer jenis ini[7][8]. Berdasarkan penelitian aplikasi sensor passive infrared receiver yang dilakukan [9] dengan perancangan sistem masukan berupa sensor yang dihubungkan dengan catu daya. Penelitian ini mengukur pancaran (coverage) daya jangkau sensor. Dengan meletakkan sensor pada suatu tempat yang tidak terhalang dengan suatu benda apapun, serta mengarahkan ke objek (manusia) yang akan dideteksi. Didapatkan hasil cakupan daya pancar sensor dengan berbagai variasi ketinggian diketahui bahwa pancaran maksimal berada pada ketinggian sensor $150 \mathrm{~cm}$ dari lantai. Jarak $500 \mathrm{~cm}$ merupakan titik terjauh untuk mendeteksi manusia.

Sebelumnya pernah dilakukanpenelitian terkait dengan alat pengukur suhu tubuh manusia tanpa adanya kontak fisik oleh [10]. Dengan pengujian alat dilakukan pada 4 orang pasien dan dilakukan pengambilan data sebanyak 5 kali untuk setiap pasien. Data yang telah diperoleh akan dibandingkan dengan termometer digital yang sudah terkalibrasi. Alat tersebut masih menggunakan sistem digital sehingga circuit board kurang efisien dalam penggunaannya.

Dalam penelitian ini dirancang termometer jenis digital yang efisien dan dapat digunakan dalam dunia kesehatan maupun kalangan umum lainnya secara aman. Thermometer yang dirancang kemampuannya mendeteksi temperatur objek dalam hitungan detik dan tanpa kontak fisik, sehingga risiko kemungkinan terjadinya infeksi nosokomial lebih kecil dengan waktu pengukuran suhu yang lebih efisien. Penunjukan yang digunakan merupakan persamaan dari satuan nilai ukurnya langsung ditampilkan dalam bentuk angka atau digit, sehingga lebih mudah diamati dan tingkat ketelitian juga lebih baik. Pengukuran suhu dilakukan melalui energi sinar infra merah dari target yang kemudian dapat digambarkan dalam bentuk suhu. Selain itu, Arduino Nano digunakan sebagai pengatur dan pengendali sistem secara keseluruhan.

\section{METODOLOGI PENELITIAN}

Dalam penelitian ini, terdiri dari perancangan perangkat keras dan perancangan perangkat lunak. Perancangan perangkat keras adalah sebagai implementasi dari non-contact thermometer yang dirancang, sedangkan perancangan perangkat lunak adalah bagaimana sistem pada non-contact thermometer ini bekerja.

\subsection{Pengimplementasian Sistem}

Pengimplementasian sistem yang dirancang, ditunjukkan pada gambar 1.

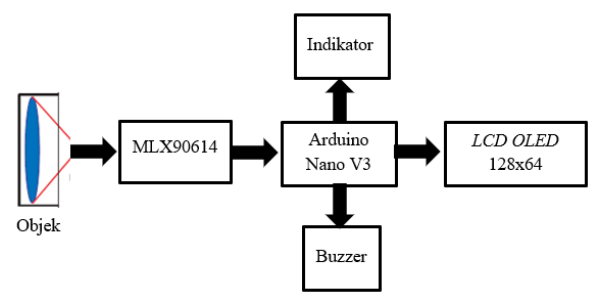

Gambar 1. Diagram Blok Non-Contact Thermometer Yang Dirancang

Sensor MLX90614[11] akan adanya pancaran infra merah masuk melalui sensor MLX90614, karena sinar infra merah mengandung energi panas maka sensor MLX90614 akan menghasilkan arus listrik. Arus listrik inilah yang akan menimbulkan tegangan kemudian diubah menjadi sinyal digital oleh sensor. 
Sinyal akan diolah menjadi harga keluaran yang sesuai dengan temperatur target. Board Arduino Nano V3 yang mengandung mikrokontroler sebagai tempat pengolahan data dari sensor, serta memberikan perintah pada rangkaian buzzer dan indikator. LCD OLED 128x64 sebagai penampil informasi suhu yang terbaca.

Sistem yang dirancang pada non-contact thermometer ini terdiri dari dua buah proses, yaitu proses scanning dan proses memory. Diagram alir proses scanning ditunjukkan oleh gambar 2.

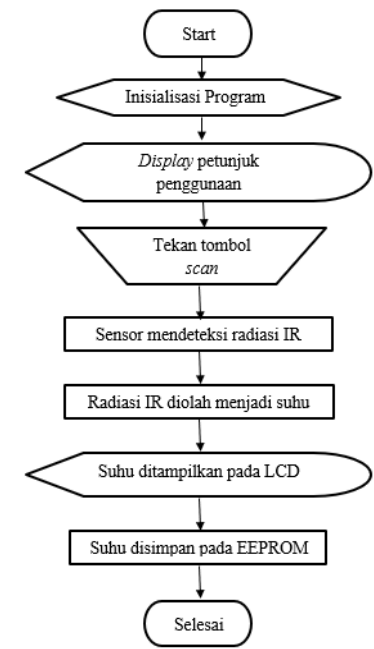

\section{Gambar 2. Diagram Alir Proses Scanning}

Saat tombol power ditekan, tegangan akan masuk ke semua rangkaian. Setelah itu Arduino Nano akan mulai melakukan inisialisasi program kemudian menampilkan petunjuk penggunaan alat pada display LCD OLED. Pada saat tombol scan ditekan maka sensor akan mendeteksi radiasi infra merah yang dipancarkan oleh objek. Data yang diperoleh dari sensor akan diolah menjadi besaran suhu oleh Arduino Nano kemudian ditampilkan pada display LCD OLED dan sekaligus akan disimpan pada memori internal (EEPROM) Arduino Nano. Diagram alir proses memory dapat dilihat pada gambar 3.

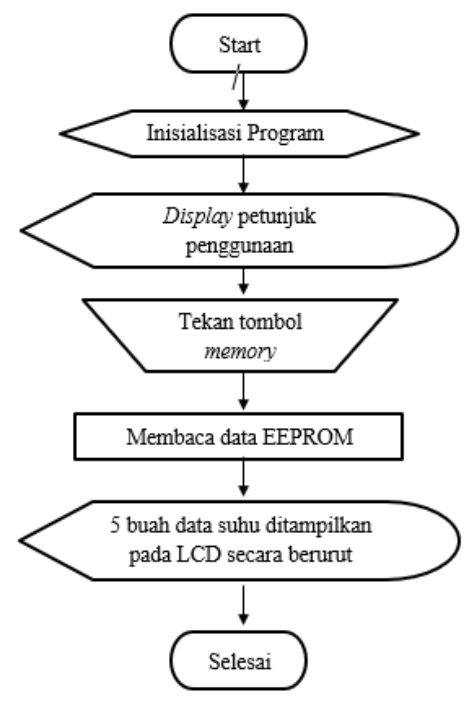

Gambar 3. Diagram Alir Proses Memory

Pengguna dapat melihat data sebelumnya yang telah diukur sebanyak 5 buah data suhu dengan menekan tombol memory. Pada saat tombol memory ditekan maka Arduino Nano akan membaca data yang telah tersimpan di EEPROM untuk ditampilkan kembali pada display LCD OLED. 


\subsection{Pengujian}

Untuk mengetahui apakah alat yang dirancang berfungsi dengan baik, dilakukan 4 pengujian yaitu pengujian suhu tubuh manusia dengan jarak yang berbeda, pengujian suhu pada bagian lengan manusia dan pengujian suhu air. Pengujian suhu tubuh manusia dengan jarak yang berbeda dilakukan dengan cara meletakkan alat di depan dahi partisipan dengan jarak yang berbeda-beda yaitu dari $1 \mathrm{~cm}$ sampai dengan $4 \mathrm{~cm}$. Pada pengujian suhu pada bagian lengan manusia, pengukuran suhu dilakukan dengan meletakkan alat di bagian lengan partisipan dengan jarak $3 \mathrm{~cm}$. Pada pengujian tahap keempat, pengambilan data dilakukan pada air yang dihangatkan dengan mengambil data pada 5 titik suhu yang berbeda yaitu $36^{\circ} \mathrm{C}$, $37^{\circ} \mathrm{C}, 38^{\circ} \mathrm{C}, 39^{\circ} \mathrm{C}$, dan $40^{\circ} \mathrm{C}$.

\section{HASIL DAN PEMBAHASAN}

Pengujian yang pertama yang dilakukan adalah pengujian suhu tubuh manusia dengan jarak berbeda. Pengujian ini dilakukan pada partisipan dengan catatan bahwa partisipan berada dalam kondisi yang sehat. Setelah pengujian dilakukan didapatkan hasil sebagaimana yang ditunjukkan oleh tabel 1.

Tabel 1. Hasil pengukuran suhu tubuh manusia dari jarak $1-4 \mathrm{~cm}$

\begin{tabular}{|c|c|c|c|c|}
\hline Jarak & $\begin{array}{l}\text { Termometer } \\
\text { Standar }\left({ }^{\circ} \mathrm{C}\right)\end{array}$ & $\begin{array}{c}\text { Non-Contact } \\
\text { Thermoter }\left({ }^{\circ} \mathrm{C}\right)\end{array}$ & $\begin{array}{c}\text { Selisih } \\
\left({ }^{\circ} \mathrm{C}\right)\end{array}$ & $\begin{array}{c}\text { Persentase } \\
\text { Error (\%) }\end{array}$ \\
\hline \multirow[t]{5}{*}{$1 \mathrm{~cm}$} & 36,4 & 36,65 & 0,25 & 0,7 \\
\hline & 36,5 & 36,39 & 0,11 & 0,3 \\
\hline & 36,6 & 36,57 & 0,03 & 0,08 \\
\hline & 36,5 & 36,72 & 0,22 & 0,6 \\
\hline & 36,5 & 36,48 & 0,02 & 0,08 \\
\hline Rata-Rata & 36,5 & 36,56 & 0,06 & $\mathbf{0 , 3 5}$ \\
\hline \multirow[t]{5}{*}{$2 \mathrm{~cm}$} & 36,4 & 36,29 & 0,11 & 0,3 \\
\hline & 36,5 & 36,54 & 0,04 & 0,11 \\
\hline & 36,6 & 36,54 & 0,06 & 0,16 \\
\hline & 36,7 & 36,57 & 0,13 & 0,35 \\
\hline & 36,6 & 36,5 & 0,1 & 0,2 \\
\hline Rata-Rata & 36,56 & 36,49 & 0,07 & 0,24 \\
\hline \multirow[t]{5}{*}{$3 \mathrm{~cm}$} & 36,6 & 36,57 & 0,03 & 0,08 \\
\hline & 36,6 & 35,9 & 0,7 & 1,91 \\
\hline & 36,6 & 36,14 & 0,46 & 1,26 \\
\hline & 36,6 & 36,29 & 0,31 & 0,85 \\
\hline & 36,6 & 35,9 & 0,7 & 1,91 \\
\hline Rata-Rata & 36,6 & 36,16 & 0,44 & 1,20 \\
\hline \multirow[t]{5}{*}{$4 \mathrm{~cm}$} & 36,5 & 35,66 & 0,84 & 2,3 \\
\hline & 36,6 & 35,41 & 1,19 & 3,25 \\
\hline & 36,5 & 35,45 & 1,05 & 2,88 \\
\hline & 36,6 & 35,51 & 1,09 & 2,98 \\
\hline & 36,6 & 35,64 & 0,96 & 2,61 \\
\hline Rata-Rata & 36,56 & 35,53 & $\mathbf{1 , 0 3}$ & 2,81 \\
\hline
\end{tabular}

Berdasarkan hasil pengujian pada Tabel 1. terlihat bahwa persentase error yang tertinggi ada pada pengujian jarak terjauh $(4 \mathrm{~cm})$ yaitu 2,81\%. Persentase kesalahan yang terkecil pada jarak pengukuran 2 $\mathrm{cm}$ yaitu $0,24 \%$, namun hal ini tidak jauh berbeda dengan hal pengujian pada jarak $1 \mathrm{~cm}$ yaitu $0,35 \%$. Hal ini menunjukkan bahwa jarak pengukuran yang paling efektif adalah pada jarak $1-2 \mathrm{~cm}$. 
Pengujian yang kedua yaitu pengujian suhu pada bagian lengan manusia. Setelah dilakukan pengujian pada 5 orang partisipan didapatkan hasil yang ditunjukkan oleh Tabel 2.

Tabel 2. Hasil pengukuran suhu pada bagian lengan manusia

\begin{tabular}{|c|c|c|c|c|}
\hline No. & Nama & $\begin{array}{c}\text { Termometer Standar } \\
\left({ }^{\circ} \mathrm{C}\right)\end{array}$ & $\begin{array}{c}\text { Non-Contact } \\
\text { Thermoter }\left({ }^{\circ} \mathrm{C}\right) \\
\end{array}$ & Selisih \\
\hline \multirow{6}{*}{1.} & \multirow{5}{*}{ Partisipan 1} & 34,7 & 36,54 & 1,84 \\
\hline & & 34,7 & 35,73 & 1,03 \\
\hline & & 34,8 & 34,65 & 0,15 \\
\hline & & 34,8 & 35,6 & 0,8 \\
\hline & & 35,1 & 35,75 & 0,65 \\
\hline & Rata-Rata & 34,82 & 35,65 & $\mathbf{0 , 8 3}$ \\
\hline \multirow{6}{*}{2.} & \multirow{5}{*}{ M. Khairul Huda } & 34,3 & 34,31 & 0,01 \\
\hline & & 34,3 & 34,57 & 0,27 \\
\hline & & 34,5 & 34,24 & 0,26 \\
\hline & & 34,8 & 35,1 & 0,3 \\
\hline & & 34,6 & 34,48 & 0,12 \\
\hline & Rata-Rata & 34,5 & 34,54 & $\mathbf{0 , 0 4}$ \\
\hline \multirow{6}{*}{3.} & \multirow{5}{*}{$\begin{array}{c}\text { Sultan Al Badrul } \\
\text { M. }\end{array}$} & 34 & 34,48 & 0,48 \\
\hline & & 34,2 & 35,32 & 1,12 \\
\hline & & 34,4 & 34,89 & 0,49 \\
\hline & & 34,5 & 34,87 & 0,37 \\
\hline & & 34,6 & 36,54 & 1,94 \\
\hline & Rata-Rata & 34,34 & 35,22 & $\mathbf{0 , 8 8}$ \\
\hline \multirow{6}{*}{4.} & \multirow{5}{*}{ Nur Cholis } & 35,1 & 35,66 & 0,56 \\
\hline & & 35,3 & 36,16 & 0,86 \\
\hline & & 35,5 & 36,14 & 0,64 \\
\hline & & 35,5 & 35,88 & 0,38 \\
\hline & & 35,3 & 35,88 & 0,58 \\
\hline & Rata-Rata & 35,34 & 35,94 & $\mathbf{0 , 6 0}$ \\
\hline \multirow{6}{*}{5.} & \multirow{5}{*}{ Agus Lim } & 35,7 & 35,81 & 0,11 \\
\hline & & 35,8 & 36,37 & 0,57 \\
\hline & & 35,7 & 36,48 & 0,78 \\
\hline & & 35,7 & 36,14 & 0,44 \\
\hline & & 35,8 & 36,46 & 0,66 \\
\hline & Rata-Rata & 35,74 & 36,25 & $\mathbf{0 , 5 1}$ \\
\hline
\end{tabular}

Berdasarkan Tabel 2. terlihat bahwa tingkat kesalahan pengukuran di bawah $1^{\circ} \mathrm{C}$. Kesalahan pengukuran tertinggi ada pada pengukuran suhu tubuh partisipan ke-3 yaitu $0,88^{\circ} \mathrm{C}$, sedangkan kesalahan terkecil ditunjukkan pada pengukuran suhu tubuh partisipan 5 yaitu $0,55^{\circ} \mathrm{C}$. Pada pengujian ini range kesalahan berkisar antara 1,4\% sampai 2,4\%. Hal ini menunjukkan bahwa dari thermometer yang dirancang memiliki akurasi yang tinggi.

Pengujian yang terakhir adalah pengujian suhu air. Pengujian ini dilakukan dengan cara membandingkan hasil pengukuran suhu air oleh thermometer yang dirancang dengan thermometer standar. Pengujian ini dilakukan pada tiga titik pengukuran. Hasil pengujian suhu air ditunjukkan oleh Tabel 3. 
Tabel 3. Hasil pengukuran suhu air

\begin{tabular}{ccccccccc}
\hline No. & $\begin{array}{c}\text { Termometer } \\
\text { Standar }\left({ }^{\circ} \text { C }\right)\end{array}$ & \multicolumn{4}{c}{ Non-Contact Thermoter $\left({ }^{\circ}\right.$ C) } & $\begin{array}{c}\text { Rata- } \\
\text { Rata }\end{array}$ & Selisih \\
\hline 1. & 36 & 36,00 & 35,98 & 36,32 & 35,58 & 35,90 & 35,96 & 0,04 \\
2. & 37 & 37,50 & 37,18 & 37,42 & 36,91 & 37,27 & 37,26 & 0,26 \\
3. & 38 & 38,11 & 38,16 & 38,11 & 37,60 & 37,66 & 37,93 & 0,07 \\
4. & 39 & 38,78 & 38,75 & 39,20 & 39,28 & 38,75 & 38,95 & 0,05 \\
5. & 40 & 40,40 & 40,38 & 40,14 & 39,74 & 39,92 & 40,12 & 0,12 \\
\hline
\end{tabular}

Berdasarkan Tabel 3. terlihat bahwa kesalahan pengukuran themometer yang dirancang dalam mengukur sangat kecil, berkisar antara $0,04^{\circ} \mathrm{C}-0,26^{\circ} \mathrm{C}$. Selain itu standar deviasi dalam pengkuran ini adalah 0,27 . Hal ini menunjukkan bahwa selain memiliki akurasi yang tinggi non-contact thermometer yang dirancang juga memiliki tingkat presisi yang tinggi.

\section{KESIMPULAN}

Dalam penelitian ini dirancang non-contact thermometer yang memanfaatkan sinar infra merah. Berdasarkan pengujian yang telah dilakukan alat ukur suhu tubuh yang dirancang telah mampu untuk mengukur suhu tubuh manusia tanpa ada kontak dengan tubuh. Selain itu, hasil pengukuran menunjukkan alat yang dirancang memiliki akurasi dan presisi yang tinggi.

\section{DAFTAR PUSTAKA}

[1] Zulfa. Pengukuran Suhu Menggunakan Termometer Inframerah. 2009;

[2] BENJAMIN O. A, AARON O. O, DONALDSON E. O. Measuring body temperature. Glob J Eng Res [Internet]. 2016;15:1-10. Available from: http://www.ncbi.nlm.nih.gov/pubmed/23240273

[3] Sund-levander M. Measurement and Evaluation of Body Temperature : Implications for Clinical Practice. 2004. 1-58 p.

[4] Sued BPR, Pereira PMA, Faria YV, Ramos JN, Binatti VB, dos Santos KRN, et al. Sphygmomanometers and thermometers as potential fomites of Staphylococcus haemolyticus: Biofilm formation in the presence of antibiotics. Mem Inst Oswaldo Cruz. 2017;112(3):188-95.

[5] Provincial Infectious Disease Advisory Comittee. Best Practices For Infection Prevention and Control of Resistant Staphylococcus aureaus and Enteroccoi. 2007.

[6] N. Kiswandani. Hasil Telusur Penurunan Jumlah Stafilokokus pada Thermometer Axilla. 2014;2-3.

[7] Adrianto AA, Basyar E. Kesesuaian Termometer Inframerah Dengan Termometer Digital Terhadap Pengukuran Suhu Aksila Pada Usia Dewasa Muda. 2018;7(2):1041-8.

[8] Akinloye BO, Onyan AO, Oweibor DE. Design And Thermometer Implementation With Of Digital Clock. 2016;15:1-10.

[9] Arifin B. Aplikasi Sensor Passive Infrared (PIR) .... 2013;(2011):39-44.

[10] Steven J, Zebua D, Suraatmadja MS, Qurthobi A. Perancangan Termometer Digital Tanpa Sentuhan Mlx90164 Infrared Temperature Sensor Arduino Uno R3. 2016;3(1):43-8.

[11] Zou W, Liu M, Wang D, Yuan Q. The Design of MLX90614 Based Kitchen Infrared Temperature Monitor Fire Alarm and A Preliminary Study of Temperature Fitting Algorithm. 